2

\title{
Developing an ANFIS-PSO Model to Estimate Mercury Emission in Combustion Flue Gases
}

\author{
Shahaboddin Shamshirband ${ }^{1,2}$, Alireza Baghban ${ }^{3}$, Masoud Hadipoor ${ }^{4}$ and Amir Mosavi 5,6,* \\ 1 Faculty of Information Technology, Ton Duc Thang University, Ho Chi Minh City, Viet Nam \\ 2 Department for Management of Science and Technology Development, Ton Duc Thang University, Ho Chi \\ Minh City, Viet Nam; shahaboddin.shamshirband@tdtu.edu.vn \\ 3 Department of Petroleum Engineering, Ahwaz Faculty of Petroleum Engineering, Petroleum University of \\ Technology (PUT), Ahwaz; Alireza_Baghban@alumni.ut.ac.ir \\ 4 Department of Chemical Engineering, Amirkabir University of Technology (Tehran Polytechnic), \\ Mahshahr Campus, Mahshahr; masoud.hadipoor@gmail.com \\ 5 Kando Kalman Faculty of Electrical Engineering, Obuda University, Budapest, Hungary \\ 6 School of Built the Environment, Oxford Brookes University, Oxford, UK; a.mosavi@brookes.ac.uk \\ * Correspondence: a.mosavi@brookes.ac.uk
}

\begin{abstract}
Accurate prediction of mercury content emitted from fossil-fueled power stations is of utmost important for environmental pollution assessment and hazard mitigation. In this paper, mercury content in the output gas of power stations' boilers was predicted using adaptive neurofuzzy inference system (ANFIS) method integrated with particle swarm optimization (PSO). The input parameters of the model include coal characteristics and the operational parameters of the boilers. The dataset has been collected from 82 power plants and employed to educate and examine the proposed model. To evaluate the performance of the proposed ANFIS-PSO model the statistical meter of MARE $\%$ was implemented, which resulted 0.003266 and 0.013272 for training and testing respectively. Furthermore, relative errors between acquired data and predicted values were between $-0.25 \%$ and $0.1 \%$, which confirm the accuracy of the model to deal nonlinearity and representing the dependency of flue gas mercury content into the specifications of coal and the boiler type.
\end{abstract}

Keywords: ANFIS-PSO; air pollution prediction; flue gas, emission, mercury; adaptive neuro-fuzzy inference system (ANFIS); particle swarm optimization (PSO); hybrid machine learning model

\section{Introduction}

Intelligent monitoring of the industrial air pollutants is of utmost important to maintain an acceptable air quality [1-4]. Among the numerous industrial pollutants, the mercury contamination has been identified as one of the most acute air pollutants produced by conventional fossil fueled power stations [5-8]. Mercury contamination can cause significant ecological hazard with a considerable effect on human well-being around the world [9-12]. As a lethal and hugely volatile metal, mercury can cause contamination of the surface streams and lakes, as well as groundwater [13]. It is the most dangerous hazard for infants and young adults as it influences the central nervous system, causing utero and severe illnesses [14]. Previous studies, e.g. [7-11] report that a substantial amount of mercury outflows to the earth comes from coal-fired power plants. In 2010, roughly 2000 mg mercury outflows to the air from various sections worldwide [15]. Coal burning had a share of $24 \%$, which is a relatively high share [16]. Power plants are in charge of around $33 \%$ Mercury outflows, and this type of emission is caused by human beings [17], and Elemental mercury emission is about $20-50 \%$ of mercury emissions which originate from combustion of coal [18, 19]. Nowadays, mercury emission from coal consumption has become a global concern [12,13,14]. In 2006, total coal consumption in China was about $40.1 \%$ of world consumption, which is equivalent to 1238.3 million tons of oil [20]. Thus, some studies suggest that the amount of mercury emission is more likely to 
increase during the next years because of more uses in developing countries [21]. The environmental protection agency of United States of America announced mercury as one of the most dangerous air pollutants. In 1999, an approximated amount of 45 tons of mercury outflows from coal-consuming plants to the environment (Alto 2000). The developing worry of this contamination in the U.S has incited government and specialists to start endeavors to recognize, estimate, and cut off on the anthropogenic emissions. As a result of the absence of cost-effective, promptly accessible and efficient practical control methodologies in the U.S, discharge of this dangerous contaminant from coalconsuming boilers are not basically under control. It gets worse when the greater of part power supply in a big country such as the United States originates from utility boilers that use coal (EPA 2001 ) and furthermore About $70 \%$ of electricity power in china is produced by burning coal, in which $50 \%$ of this coal is burned in coal-based power plants [22-24].

In 1998, Paying attention to the enormous potential for environmental dangers, EPA proposed a request to ask coal-consuming plants to publish information on the amounts of mercury contaminant outflows from their systems. This request was designed to gather information in three primary stages precisely. The first and principal stage was intended to collect all standard data on coal-burning power plants around the U.S. afterward, as the second stage of the program, analyzed feed data at the entrance of every plant during a year were collected. Eventually, in the third phase, EPA chose 84 out of 1084 plants to gather data of mercury emission in some specified points within the selected plants. This selection was based on some statistic activities on the feed specifications and also the operational structure of each plant. Resulted in information from the third phase of the program was evaluated. Representing correlations were developed to predict the emission of mercury in each plant concerning coal qualities and operating conditions. It was found that the best input data were characteristics of coal, for example, the concentration of mercury, heating value, chlorine sulfur, operating parameters such as temperatures and pressures and also yield parameters in boilers such as the amount of mercury oxidization. Beside abovementioned backgrounds, artificial intelligence approaches are powerful tools to forecast parameters by finding correlations between variables. This kind of networks can see the nonlinear relationship between parameters, so they are valuable method [25].

A deep understanding of the power plant is needed to control the amounts of mercury emissions. Therefore, an accurate estimation of emission is of utmost important to control and reduce mercury emission [26]. Numerous investigations were published in the literature regarding applications of artificial intelligence approaches. Computational intelligence has been both used to predict the amount of mercury emission and also to model the elimination of elemental mercury from boilers' outlet gas [27]. Dragomir and Oprea [28] present a multi-agent prediction tool for intelligent monitoring of the pollutants on the power plants. They used a model based on neural networks to predict the amount of $\mathrm{SO}_{2}, \mathrm{NO}_{x}$, particulate matters (PMs), and mercury emissions. Jensen et al. [29] presented a study on the relationship between mercury in the flue gas and coal specifications and the type of boiler using a multilayer perceptron model. They derived an accurate model with a correlation coefficient of 0.9750 . Antanasijevic et al. [30] developed a prediction model using neural networks and genetic algorithm (GA) to accurately calculate the amount of PM10 emissions for up to two years ahead. Zhao et al. [31] used support vector machine to develop a model which provided better performance and accuracy. In 2016, Wang et al. [32] worked on the application of GA-back propagation (GA-BP) for predicting the amount of mercury component in flue gases of 20 different coal-fired boilers. Correlation coefficient training data points was as high as 0.895 , and they showed that GA-BP is a promising method for this goal. Li et al. [33] employed computational intelligence approach to cut off on the elemental mercury in coal-fired boilers, and finally, they found that the increment of capture efficiency can approximately improve up to $15 \%$.

Although, the application of machine learning for prediction of pollutants and mercury emissions is well stablished within the scientific communities, the potential of the novel machine learning models (e.g., ensembles and hybrids) is still not explored for mercury prediction. In particular a wide range of novel hybrid machine learning methods have been recently developed to deliver higher accuracy and performance [34-36]. For instance, the hybrid model of ANFIS-PSO 
which is an integration of adaptive neuro-fuzzy inference system (ANFIS) and particle swarm optimization (PSO) has shown to deliver promising results [37]. The aim of the present study is to find a reliable relationship between elemental mercury in the output gas, the specification of feed, and the type of boilers by utilizing an ANFIS-PSO based approach.

\section{Model development}

The description of the hybrid model of ANFIS-PSO is presented in [37]. Note that, when there is not enough data on the detailed information of an operating power plant, it is extremely difficult to build a precise model to predict the amount of mercury outflow. In the present study, an endeavor has made to develop a model to predict mercury outflows from boilers at some specified testing locations. In this kind of locations, every single factor that may influence the mercury discharge is considered and incorporated into the model. A total number of 82 data points were gathered from literature to train and evaluate the model [29]. The concentration of mercury in the inlet feed, ash content, chlorine content, the heating value of coal, sulfur content, and temperature were chosen as the most effective variables. This data bank comprises a total number of 82 data points, from which $75 \%$ were used as training, and the rest of them were exploited testing samples. In the developed ANFIS model, six previously mentioned parameters were considered as input parameters, and the elemental mercury emission was selected as the target variable. Furthermore, the PSO algorithm was used to find the optimized Gaussian membership function parameters of the proposed ANFIS model.

The method of ANFIS is proposed by Jang $[38,39]$ and is a versatile and very intelligent hybrid system. ANFIS approach can be expressed as a complete collaboration between computing activities and neuro-fuzzy system [40]. This method integrates natural and neural networks and uses their strength into its advantage. Such methodology exploits back-propagation calculation from the information gathering process to make the essential basics of the fuzzy system. Its framework is related to an arrangement of fuzzy IF-THEN rules which have learning ability to estimate nonlinear functions. Basics of the ANFIS method are approximately similar to a fuzzy system developed by Takagi-Sugeno-Kang [41, 42]. In reverse spread learning capability of the ANFIS method, which is based on the calculation of derivatives of squared errors in a backward manner form output nodes to the input ones, this method constructs and utilizes robust learning methodology based on gradient least-squares approach. To determine the consequence factors in the forward section, the least square approach is utilized. Then the preset parameters will reset by gradient descent in the regressive advance [43]. The adaptive network is constructed of five layers. Figure 1 shows these layers, their nodes and connections with the assumption of two inputs to the fuzzy inference system expressed by " $\mathrm{x}$ " and " $\mathrm{y}$ " and a single output of " $\mathrm{f}$ ". As an explanation about the configuration of ANFIS, it must be noted that two fuzzy 'if-then' rules are utilized which they follow sugeno FIS as:

$$
\begin{array}{ll}
f_{1}=P_{1}+q_{1} y+r_{1} & \text { assume } \mathrm{x}=\mathrm{A}_{1}, \mathrm{y}=\mathrm{B}_{1} \\
f_{2}=P_{2}+q_{2} y+r_{2} & \text { assume } \mathrm{x}=\mathrm{A}_{1}, \mathrm{y}=\mathrm{B}_{1}
\end{array}
$$

Fuzzification layer, which is the first layer of the structure produces all membership grades for each variable. Node functions in this layer can be defined as follows:

$$
\begin{aligned}
& O_{1, i}=\mu_{A i}(x) \quad i=1,2 \\
& O_{1, i}=\mu_{B i-2}(x) \quad i=3,4
\end{aligned}
$$

Memberships of a fussy set are $\left(A_{i}, B_{i}\right)$ and $\mathrm{O}_{1, i}$ represents the resulted value from the $i^{\text {th }}$ node of the first layer. The input signals are generated by the nodes of layer 2 .

$$
O_{2, i}=w_{i}=\mu_{A i}(x) \times \mu_{B i(x)} \quad i=1,2
$$

The nodes of the third layer are used to compute the following parameter: 


$$
O_{3, i}=\bar{\omega}=\frac{W_{i}}{W_{1}+W_{2}} \quad i=1,2
$$

Where $W_{i}$ is ruled firing strengths of node $i$ which has a normalized firing strength of $\omega_{i}$. Results of layer four can be written as follows:

$$
O_{4, i}=\bar{\omega} f_{i}=\bar{\omega} i\left(P_{i}+q_{i} y+r_{i}\right) \quad i=1,2
$$

In this notation $p_{i}, q_{i}$, and $r_{i}$ are called consequent parameters. Eventually, the general output can be defined as follows, which is calculated in the nodes of layer 5 :

$$
O_{5, i}=\sum_{i=1}^{2} \bar{\omega}_{i} f_{i}=\frac{\omega_{1} f_{1}+\omega_{2} f_{2}}{W_{1}+W_{2}}
$$

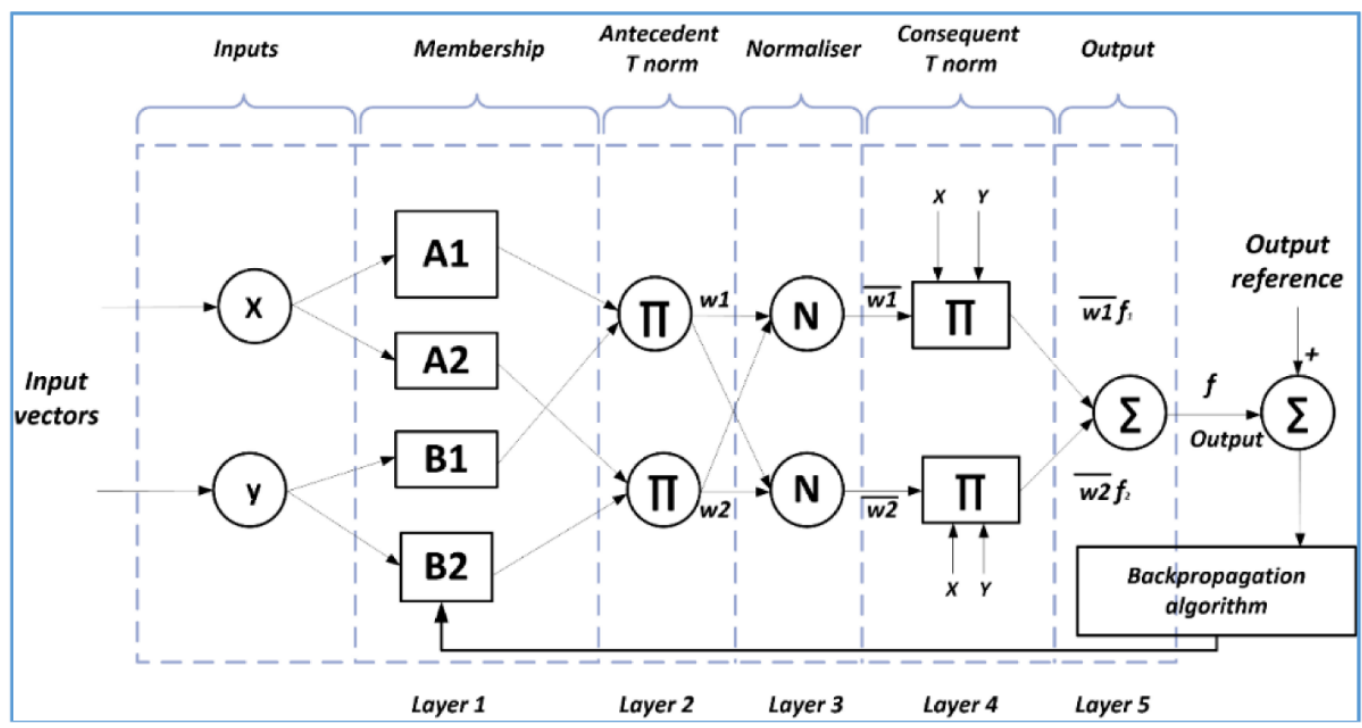

Figure 1. A schematic view of the ANFIS intelligent system.

ANFIS, has shown promising results in a wide range of applications for developing prediction models [44-47]. However, optimization of the model parameters can dramatically improve the quality and accuracy of modeling [37]. For that matter, a huge number of optimization methodologies, such as PSO, are available to reinforce the parameters and answers of the ANFIS system [48]. PSO is extraordinary compared to other approaches with the end goal of optimization. This study takes the benefits of this algorithm.

Particle swarm optimization method has been inspired from birds behavior seeking food [49, 50]. In this model, particles update their places and pathways based on their and others information; so it was proposed that the particle possess a memory function. The optimization process is based on competition and collaboration between particles. When PSO is used to solve optimization problems, one can follow the particles state by their pathways, and velocities. Three vectors $X_{i}, V_{i}, P_{b e s t i}$ are introduced to explain the properties of a particle: $X_{i}$ is the current place; $V_{i}$ the current speed; Pbest $t_{i}$ the best spatial placement sought by the particle and gbest $t_{i}$ is the optimal solution searched by the whole group of particles. The position and pathway of the particle will be updated gradually, based on the following formula:

$$
v(k+1)=v(k)+c_{1} \operatorname{rand}(0,1) \times[\operatorname{pbest}(k)-\operatorname{persent}(k)]+c_{2} \operatorname{rand}(0,1) \times[\operatorname{gbest}(k)-\operatorname{persent}(k)]
$$

$$
\text { present }(\mathrm{k}+1)=\text { present }(\mathrm{k})+\mathrm{v}(\mathrm{k}+1)
$$

Where, $v($ ) is particle speed in $k$ th and $k+1$ th iterations; present ( ) is particle position; $c 1, c 2$ are learning constants which are greater than zero, and a random number between $[0,1]$ is denoted using 
rand( ). Formula (7) represents the updating process of the particle's speed, which includes a particle's historical velocities and personal and global best positions [51].

\section{Results}

The amount of mercury emission was estimated using an ANFIS approach. Emission of mercury into the environment generally is a strong function of mercury six previously mentioned variables. We used MATLAB software to construct our model. A Gaussian function was used to optimize the parameters. In addition to that, the total number of 10 clusters were utilized in the ANFIS hybrid system. Optimization was conducted on a total number of parameters that were determined by:

$$
\mathrm{N}_{T}=\mathrm{N}_{c} \mathrm{~N}_{v} \mathrm{~N}_{m f}
$$

Where the number of parameters for undergoing optimization is denoted by $\mathrm{N}_{\mathrm{T}}$, and $\mathrm{N}_{\mathrm{mf}}$, is used to show the number of Gaussian membership functions that are used, Nv and Nc show how many variables, and clusters are used in the model, respectively. It is noteworthy to state that in this study, two membership functions, seven input and output variables, and 10 clusters are used. Eventually, using a PSO algorithm, optimization was conducted for 140 tuning parameters. As is shown in Figure 2 , to evaluate the functionality of the PSO algorithm, a root means square error (RMSE) analyze was used. Results show that in a total number of 1000 iterations, the minimum value of RMSE is touched. Figure 3 indicates train membership function parameters for each input variables. It is seen that the results of the presented model are in good agreement with the obtained data, which is the result of great learning capability of the developed ANFIS model. Figure 4 illustrates the obtained data of mercury emissions versus the test and training of ANFIS hybrid system.

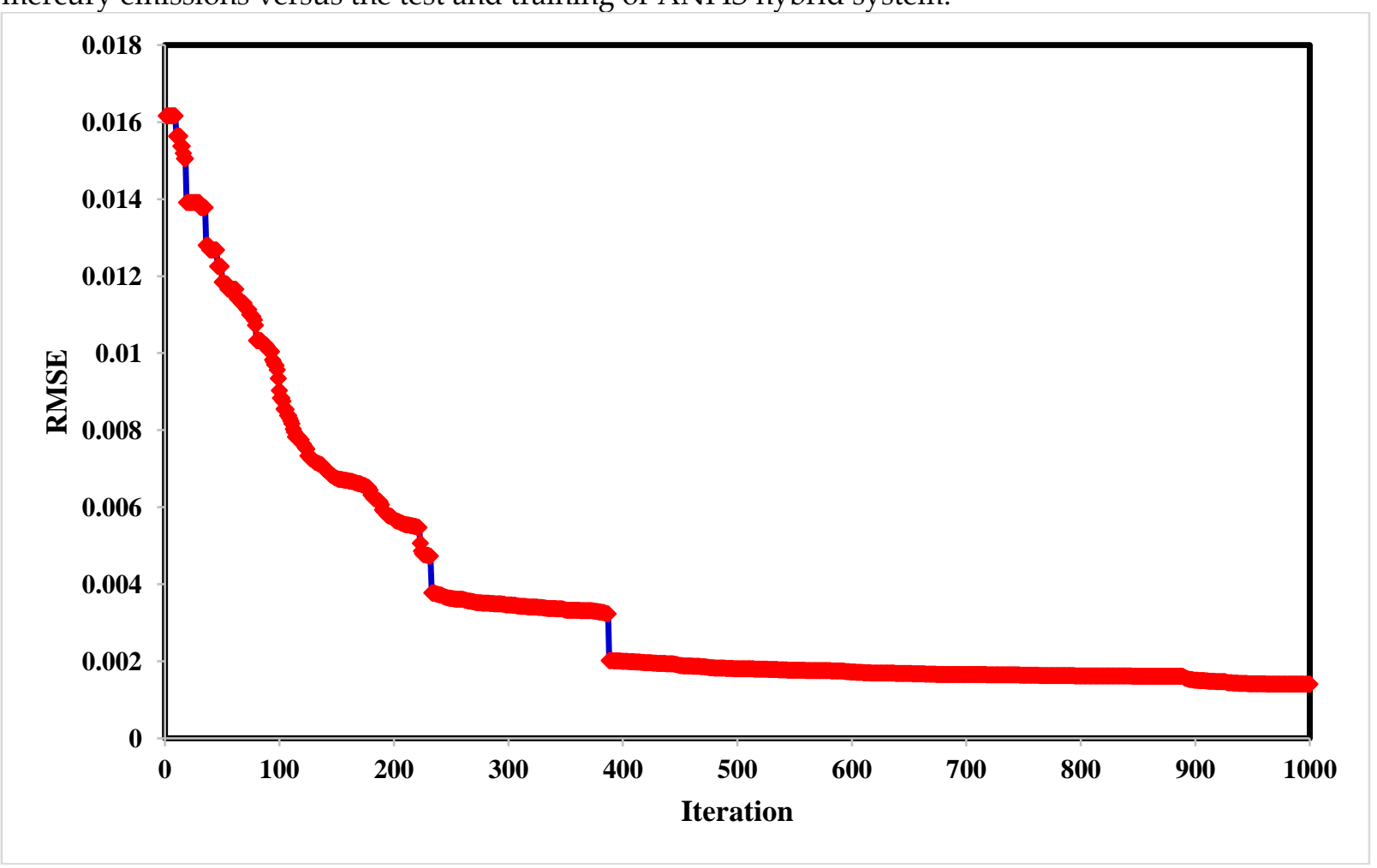

Figure 2. Root mean square errors versus number of iterations. 

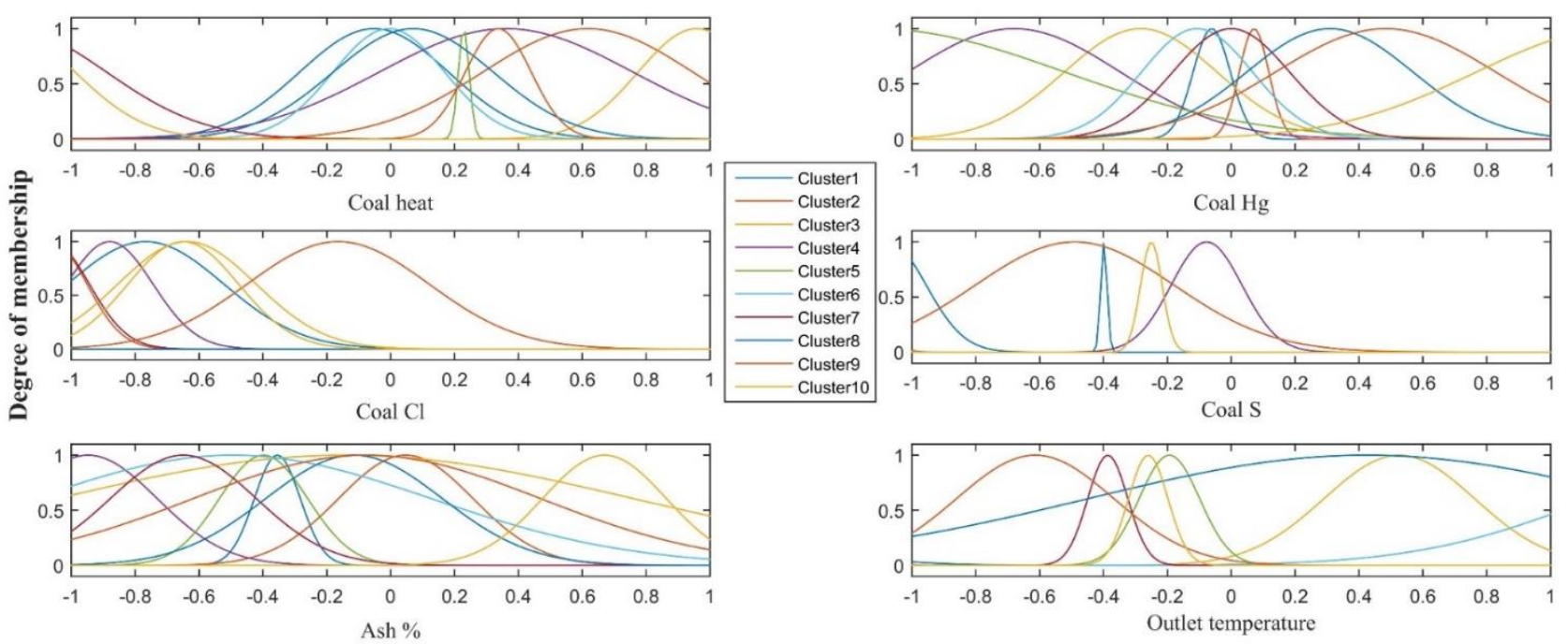

Figure 3. Trained membership function parameters.

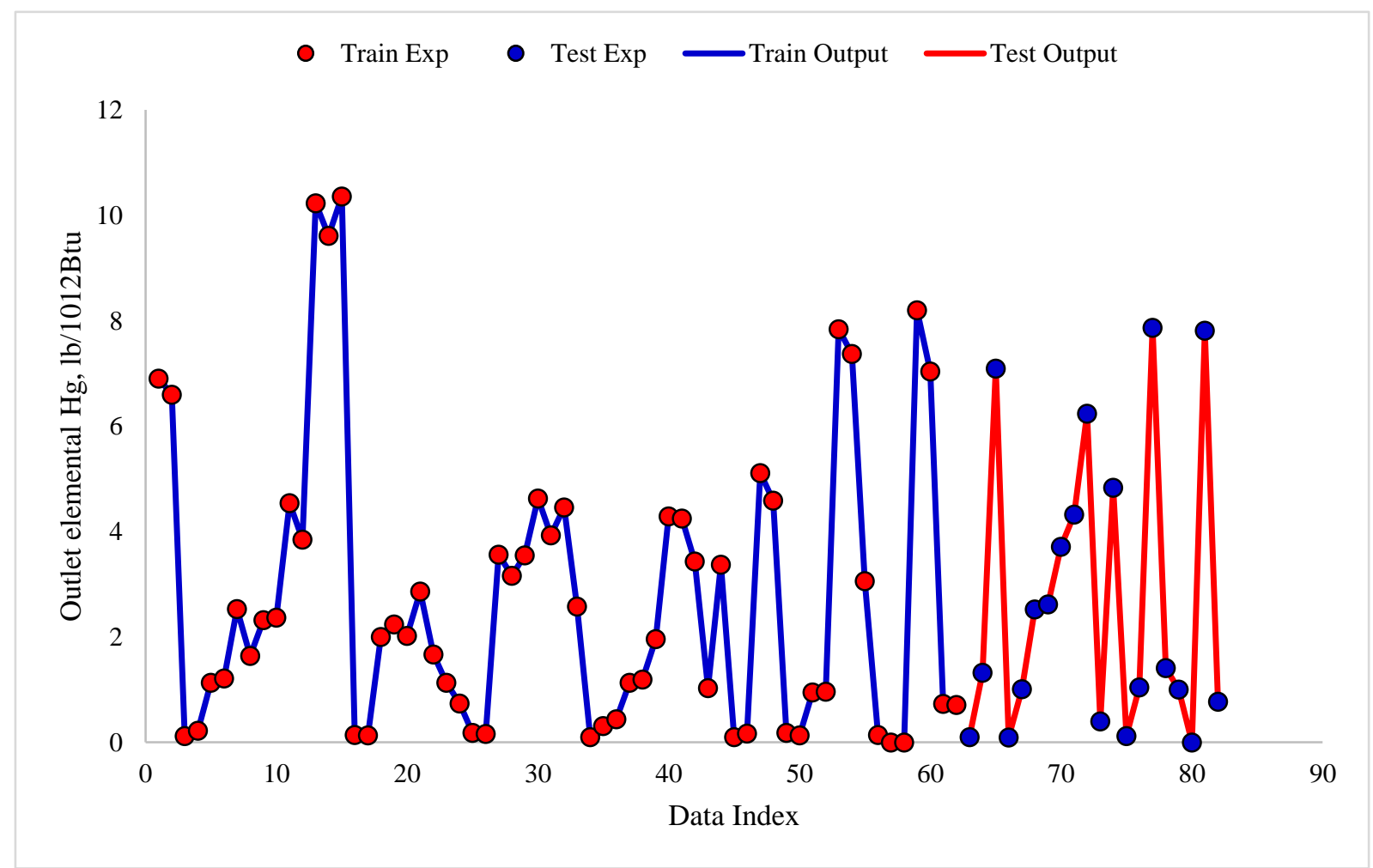

Figure 4. Obtained data form plants and ANFIS values for mercury emissions in the stages of training and testing.

As is shown in Figure 5, actual and predicted mercury emissions are located on a straight line with an approximate slope of $1\left(45^{\circ}\right.$ line) which indicates that the obtained information and ANFIS predicted ones are in good agreement. The obtained cross-fit line in both test and training data sets have an $R^{2}$ Equal to 1, which shows the accurateness of the model. To compare the results of the model and evaluate its precision, the method of mean absolute relative error is used. For training and testing steps, using mean absolute relative error percentage (MARE \%) method, percentage values of 
202 Figure 6. Low relative deviations are observed due to accurately-predicted values. Different statistical 203 analyses were also presented in Table 1 for the suggested model.

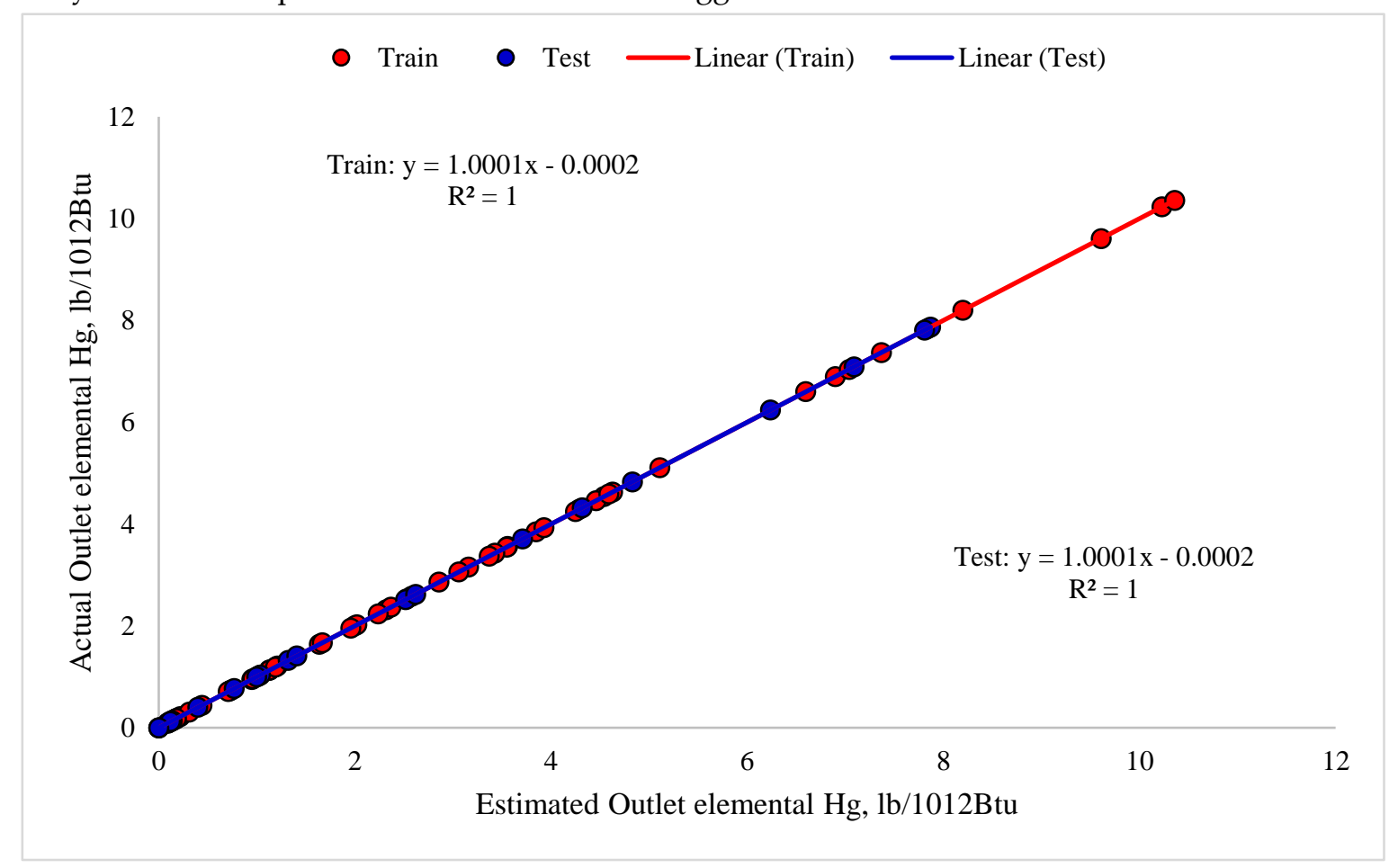

Figure 5. Regressions derived between estimated and collected data of mercury emissions.

206

Table 1. Statistical analysis of the model for all phases.

\begin{tabular}{ccc}
\hline & Train & Test \\
\hline $\mathbf{R}^{2}$ & 1.000 & 1.000 \\
MSE & $1.40 \mathrm{E}-07$ & $1.39 \mathrm{E}-07$ \\
MRE (\%) & 0.037 & 0.044 \\
\hline
\end{tabular}




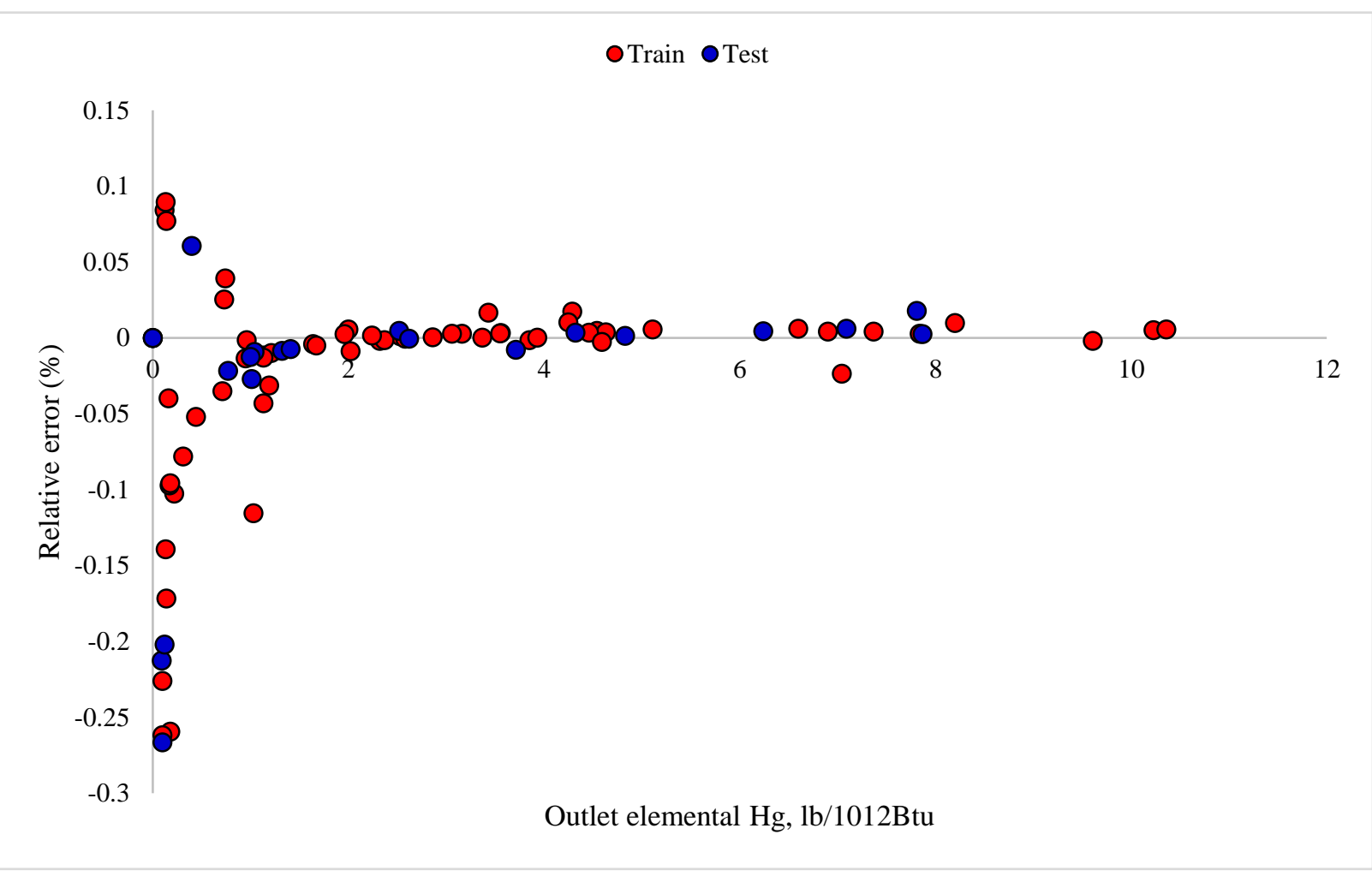

Figure 6. Deviation between the obtained data from plants and predicted mercury emissions.

\section{Conclusions}

Emission of mercury is known as one of the most perilous environmental contamination. In this study, a comprehensive literature review was done, and a predictive model was built to predict the amount of mercury emission based on the characteristics of the coal supply, operational conditions, and so forth. The presented model is based on the ANFIS system, which utilizes a PSO algorithm to estimate the amount of mercury emission to the environment. Data from 82 power plants have been used to train and develop the ANFIS model. The MARE\% for training and testing were 0.003266 and 0.013272 , respectively. Furthermore, relative errors between acquired data and predicted values were between $-0.25 \%$ and $0.1 \%$, which confirm the accuracy of PSO-ANFIS model. It was seen that for both training and testing parts, the coefficient of determination was calculated to equal to unity, which reflects the accuracy of the proposed ANFIS-PSO based model.

Author Contributions: For research articles with several authors, a short paragraph specifying their individual contributions must be provided.

Conflicts of Interest: The authors declare no conflict of interest.

\section{References}

1. Hong E, Lee S, Kim GB, Kim TJ, Kim HW, Lee K, et al. Effects of environmental air pollution on pulmonary function level of residents in Korean industrial complexes. International Journal of Environmental Research and Public Health. 2018;15.

2. Jirik V, Brezna B, Machaczka O, Honkysova S, Miturova H, Janout V. Associations between air pollution in the industrial and suburban parts of Ostrava city and their use. Environmental Monitoring and Assessment. 2017;189.

3. Lyanguzova IV. Dynamic trends of heavy metal contents in plants and soil under different industrial air pollution regimes. Russian Journal of Ecology. 2017;48:311-20.

4. Oyjinda P, Pochai N. Numerical Simulation to Air Pollution Emission Control near an Industrial Zone. Advances in Mathematical Physics. 2017;2017. 
5. Gao W, Jiang W, Zhou M. The spatial and temporal characteristics of mercury emission from coal combustion in China during the year 2015. Atmospheric Pollution Research. 2019;10:776-83.

6. Marczak M, Budzyń S, Szczurowski J, Kogut K, Burmistrz P. Active methods of mercury removal from flue gases. Environmental Science and Pollution Research. 2019;26:8383-92.

7. Sung JH, Back SK, Lee ES, Jang HN, Seo YC, Kang YS, et al. Application of powdered activated carbon coating to fabrics in a hybrid filter to enhance mercury removal. Journal of Environmental Sciences (China). 2019;80:58-65.

8. Zhao S, Pudasainee D, Duan Y, Gupta R, Liu M, Lu J. A review on mercury in coal combustion process: Content and occurrence forms in coal, transformation, sampling methods, emission and control technologies. Progress in Energy and Combustion Science. 2019:26-64.

9. Bourtsalas AC, Themelis NJ. Major sources of mercury emissions to the atmosphere: The U.S. case. Waste Management. 2019;85:90-4.

10. Budnik LT, Casteleyn L. Mercury pollution in modern times and its socio-medical consequences. Science of the Total Environment. 2019;654:720-34.

11. Li X, Li Z, Wu T, Chen J, Fu C, Zhang L, et al. Atmospheric mercury emissions from two pre-calciner cement plants in Southwest China. Atmospheric Environment. 2019:177-88.

12. Zhou H, Hopke PK, Zhou C, Holsen TM. Ambient mercury source identification at a New York State urban site: Rochester, NY. Science of the Total Environment. 2019;650:1327-37.

13. Zhao S, Duan Y, Chen L, Li Y, Yao T, Liu S, et al. Study on emission of hazardous trace elements in a 350 MW coal-fired power plant. Part 1. Mercury. Environmental Pollution. 2017;229:863-70.

14. Mahavong K, Pataranawat $\mathrm{P}$, Chinwetkitvanich S. Mercury contamination in environment surrounding coal-fired power plant. International Journal of GEOMATE. 2017;12:71-7.

15. Amap/Unep. Technical background report for the Global Mercury Assessment 2013. Arctic Monitoring and Assessment Programme, Oslo, Norway/UNEP Chemicals Branch Geneva, Switzerland. 2013.

16. Burmistrz P, Kogut K, Marczak M, Zwoździak J. Lignites and subbituminous coals combustion in Polish power plants as a source of anthropogenic mercury emission. Fuel Process Technol. 2016;152:250-8.

17. Alto P. Power plants and mercury, environmental issues. CA: Electric Power Research Institute; 2001.

18. Carpi A. Mercury from combustion sources: a review of the chemical species emitted and their transport in the atmosphere. Water Air Soil Pollut. 1997;98:241-54

19. Srivastava RK, Hutson N, Martin B, Princiotta F, Staudt JX. Control of mercury emissions from coal-fired electric utility boilers. Environmental Science \& Te chnology. 2006:1385-93.

20. Zhang L, Zhuo Y, Chen L, Xu X, Chen C. Mercury emissions from six coal-fired power plants in China. Fuel Process Technol. 2008;89:1033-40.

21. Streets DG, Zhang Q, Wu Y. Projections of global mercury emissions in 2050. Environ Sci Technol. 2009;43:2983-8.

22. Tian H, Wang Y, Cheng K, Qu Y, Hao J, Xue Z, et al. Control strategies of atmospheric mercury emissions from coal-fired power plants in China. Journal of the Air \& Waste Management Association. 2012;62:57686.

23. Tian H, Wang Y, Xue Z, Qu Y, Chai F, Hao J. Atmospheric emissions estimation of Hg, As, and Se from coal-fired power plants in China, 2007. Sci Total Environ. 2011;409:3078-81.

24. You CFa, Xu XC. Coal combustion and its pollution control in China. Energy. 2010;35:4467-72.

25. Baghban A, Ahmadi MA, Shahraki BH. Prediction carbon dioxide solubility in presence of various ionic liquids using computational intelligence approaches. The Journal of supercritical fluids. 2015;98:50-64.

26. Song J, Romero CE, Yao Z, He B. A globally enhanced general regression neural network for on-line multiple emissions prediction of utility boiler. Knowledge Based Syst. 2017;118:4-14.

27. $\mathrm{Li} \mathrm{Q}, \mathrm{Wu}$ J, Wei H. Reduction of elemental mercury in coal-fired boiler flue gas with computational intelligence approach. Energy. 2018;160:753-62.

28. Dragomir EG, Oprea MJIPV. A Multi-Agent System for Power Plants Air Pollution Monitoring. 2013;46:8994.

29. Jensen RR, Karki S, Salehfar H. Artificial neural network-based estimation of mercury speciation in combustion flue gases. Fuel Processing Technology. 2004;85:451-62.

30. Antanasijević DZ, Pocajt VV, Povrenović DS, Ristić MĐ, Perić-Grujić AA. PM10 emission forecasting using artificial neural networks and genetic algorithm input variable optimization. Journal of Science of the Total Environment. 2013;443:511-9. 
31. Zhao B, Zhang Z, Jin J, Pan W-P. Modeling mercury speciation in combustion flue gases using support vector machine: Prediction and evaluation. J Hazard Mater. 2010;174:244-50.

32. Wang F, Tian G, Wang X, Liu Y, Deng S, Wang H, et al. Application of genetic algorithm-back propagation for prediction of mercury speciation in combustion flue gas. Clean Technologies Environmental Policy. 2016;18:1211-8.

33. Li Q, Wu J, Wei H. Reduction of elemental mercury in coal-fired boiler flue gas with computational intelligence approach. J Energy. 2018;160:753-62.

34. Ardabili SF, Najafi B, Alizamir M, Mosavi A, Shamshirband S, Rabczuk T. Using SVM-RSM and ELM-RSM approaches for optimizing the production process of methyl and ethyl esters. Energies. 2018;11.

35. Qasem SN, Samadianfard S, Nahand HS, Mosavi A, Shamshirband S, Chau KW. Estimating daily dew point temperature using machine learning algorithms. Water (Switzerland). 2019;11.

36. Torabi M, Mosavi A, Ozturk P, Varkonyi-Koczy A, Istvan V. A Hybrid Machine Learning Approach for Daily Prediction of Solar Radiation. Lecture Notes in Networks and Systems: Springer; 2019. p. 266-74.

37. Basser H, Karami H, Shamshirband S, Akib S, Amirmojahedi M, Ahmad R, et al. Hybrid ANFIS-PSO approach for predicting optimum parameters of a protective spur dike. Applied Soft Computing Journal. 2015;30:642-9.

38. Roger JJ-S. ANFIS: adaptive-network-based fuzzy inference system. IEEE Transactions on Systems, Man, and Cybernetics. 1993;23:665-85.

39. Jang J-SR. Fuzzy Modeling Using Generalized Neural Networks and Kalman Filter Algorithm. AAAI. 1991;91:762-7.

40. Baghban A. Application of the ANFIS strategy to estimate vaporization enthalpies of petroleum fractions and pure hydrocarbons. Pet Sci Technol. 2016;34:1359-66.

41. Takagi T, Sugeno M. Fuzzy identification of systems and its applications to modeling and control. transactions on systems, man, and cybernetics. 1985:116-32.

42. Sugeno M, Kang. Structure identification of fuzzy model. Fuzzy Sets Syst. 1988;28:15-33.

43. Baghban A, Bahadori M, Ahmad Z, Kashiwao T, Bahadori. Modeling of true vapor pressure of petroleum products using ANFIS algorithm. Pet Sci Technol. 2016;34:933-9.

44. Dehghani M, Riahi-Madvar H, Hooshyaripor F, Mosavi A, Shamshirband S, Zavadskas EK, et al. Prediction of hydropower generation using grey Wolf optimization adaptive neuro-fuzzy inference system. Energies. $2019 ; 12$.

45. Mosavi A, Edalatifar M. A Hybrid Neuro-Fuzzy Algorithm for Prediction of Reference Evapotranspiration. Lecture Notes in Networks and Systems: Springer; 2019. p. 235-43.

46. Mosavi A, Salimi M, Ardabili SF, Rabczuk T, Shamshirband S, Varkonyi-Koczy AR. State of the art of machine learning models in energy systems, a systematic review. Energies. 2019;12.

47. Rezakazemi M, Mosavi A, Shirazian S. ANFIS pattern for molecular membranes separation optimization. Journal of Molecular Liquids. 2019;274:470-6.

48. Baghban A, Kashiwao T, Bahadori M, Ahmad Z, Bahadori A. Estimation of natural gases water content using adaptive neuro-fuzzy inference system. Pet Sci Technol. 2016;34:891-7.

49. Chen G, Huang X, Jia J, Min Z. Natural exponential inertia weight strategy in particle swarm optimization. 2006 6th World Congress on Intelligent Control and Automation: IEEE; 2006. p. 3672-5.

50. El-Gallad A, El-Hawary M, Sallam A, Kalas A. Enhancing the particle swarm optimizer via proper parameters selection. IEEE CCECE2002 Canadian Conference on Electrical and Computer Engineering Conference Proceedings (Cat No 02CH37373): IEEE; 2002. p. 792-7.

51. Meng X, Pian Z. Intelligent Coordinated Control of Complex Uncertain Systems for Power Distribution and Network Reliability: Elsevier; 2015. 